\title{
Anaesthesia for off pump coronary artery bypass- Recent updates
}

India is considered as a hub for cardiac patient.There is exponential increase in number of patients across the globe as well as in india.As diagnostic modalities (facilites for invasive cardiac imaging) are increasing day by day, more and more patients are being subjected for percutaneous coronary angioplasties and bypass surgeries. The basic difference between western scenario and indian scenario is indian surgeons are more favouring technically more challenging off pump coronary artery bypass technique vs western surgeon who are more inclined towards less challenging on pump surgeries $^{1}$. So indian anesthesiologist are more experinced in managing OPCAB more effectively where $90 \%$ of cardiac surgery is off pump in contrast to western world where ratio is reverse.

\section{Preoperative evaluation:}

Preoperative evaluation includes patients general and medical history, previous surgical history, recent chest pain,comorbid conditions like diabetes mallietus, hypertension, stroke, kidney disease. Detailed general and systemic examination is performed to assess functional status of the patient. Allens test is not performed at authors institute while dorsalis pedis pulsations are checked routinely to assess peripheral vascular disease, and generally femoral arterial canulation is avoided on the side of absent dorsalis pedis pulsation. Routine investigations include complete blood count, urine examination, liver function tests, kidney function test,coagulation profile,fasting and post prandial blood sugar leves, glycosylated haemoglobin,12 lead electrocardiogram, 2 D echocardiogram². Angiogram is assessed by anesthesiologist to know possiblility of intraoperative crash and need to go on emergency bypass. Critical left main diases, and diffuse small caliber vessels with persistent ischemia are predictors of need for going on emergency bypass. Color dopplor of carotid arteries are done routinely to assess concomittant carotid block and patient risk stratification. Risk stratification is generally done by well established online risk calculator programmes like EUROSCORE $2^{3}$.

\section{Preoperative medication:}

Clopidogreal should be stopped 5 days prior to surgery and ticagrelor 7 days prior to surgery. Aspirin is generally contined and does not increase risk of postoperative bleeding. At authors institution, even clopidogrel is also continued 48 hours before surgery with little increased risk of bleeding.Beta blockers and statins are continued while ACE inhibitors and ARBS and diureticsare withheld 24 hours prior to surgery.Patient recieves anxiolytic in night with nil orally for 8 hours.Betadine bath and enema is given one night prior to surgery.

\section{Intraoperative management ${ }^{4}$ :}

16 guage canula is placed under local anesthesia.Left sided radial canulation is done under local anesthesia.Arterial blood gas and blood sugars readings are taken as a baseline.Invasive blood pressure monitoring is started.Electrocardiogram leads are stick on back side with 5 lead placement along with cautery paddles.Warmer is started and airconditions are made off till patient is induced.patient is induced with combination of midazolam, fantanyl ,propofol,sevoflurande and muscle relaxant of rocuronium or vecuronium.patient is intubated with appropriate size endotracheal tube, and left femoral canulation along with right internal jugular canulation is done .whole body painting and draping is done.Magnesium sulphate 2 grams is given to prevent postoperative atrial fibrillation.5 lead Electrocardiogram, Spo2, end tidal carbon dioxide monitor, nasal tempreature, central venous pressure and invasive arterial pressure are routinely monitored.pulmonary artery catheter is not favoured.

Before sternotomy high dose fantanyl is again repeated.Tidal volumes are adjusted as per requirement of the surgeon to dissect left internal mammary artery and intermittently ventilation is made off keeping an eye on end tidal carbon diaoxide.

Patient is heparinized with surgeons preference ( between $2 \mathrm{mg} / \mathrm{kg}$ to $4 \mathrm{mg} / \mathrm{kg}$ ) to keep activated clotting time in range of 250 to 350 seconds. One ionotrope( Preferable adrenailine) and one dilator( preferably Nitroglycerine) is kept in hand to immediately manage haemodynamic variables.

During left anterior descending and diagnoal aretery anastomosis, there is no much haemodyanamic variation except for little fall in blood pressure.The haemodynamic changes are severe with obtuse marginal artery grafing and right coronary artery branches grafting.The combination of trendlenburg position, fluid loading, and bolus dosing of pheynylephrine or noradrenaline can easily manage haemodynamic. Extreme cases of haemodynamic fluctuation,right pleura can be opened to accomodate the right ventricle, which can enhance blood perssure furher.The target of blood pressure kept is mean arterial pressure of around 55 $\mathrm{mm} \mathrm{Hg}$, and any fall below can lead to slowing of heart or ventricular fibrillation, which is immediately treated with 
repositioning of heart.If severe left ventricular dysfunction is there which is not tolerating extreme degrees of positioning,preoperative placement of intraaortic baloon pump can be sought. With the combination of above things, expert anesthetist can manage the haemodynamics very well even with low ejection fractions of $25-30 \%$ with off pump technique including at authors institute where $99 \%$ of coronary artery bypass are off pump.

After completion of distal grafting, for proximal grafting ,blood pressure is reduced to $90 \mathrm{~mm} \mathrm{Hg}$ systolic so as to apply partial cross clamp to aorta.once proximal grafting is over,heparin is neutralized with protmine in 1:1 ratio.after heparin neutralization,arterial blood gases are repated and compared with baseline values to check potassium levels,acidosis, and hematocrit.The blood is started according to report in $A B G$ if $\mathrm{Hb}$ is less than 10 grams\%.

Once procedure is over,patient is shifted to intensive care unit on ventilator with invasive monitoring.patient is actively warmed,haemodynamic assesseed and extubaed at the end of 4 hours.

Various regimens are available for postoperative pain control with equal efficacy .Opoid and NSAID based analgesic regimens are popular,currently alpha 2 agonist, dexmedetomidine is getting popular as postoperative analgesic. paracetamol and tramadol combination is used at authors institute with good result.

The combination of proper preoperative evaluation, strict management of haemodynamics and vigilance are keys for successful anesthetic management of off pump coronary artery bypass.

\section{Dr Nikhil Mudgalkar}

Address for correspondence: Dr Nikhil Mudgalkar, Professor,Department of Anaesthesia, Prathima Institute of Medical Sciences, Karimnagar, Telangana, India.

\section{Email: drniks2000@yahoo.com}

\section{REFERENCES}

1. Bakaeen FG, Shroyer AL, Gammie JS et al. Trends in use of off-pump coronary artery bypass grafting: Results from the Society of Thoracic Surgeons Adult Cardiac Surgery Database. J Thorac Cardiovasc Surg. 2014 Sep;148(3):8563, 864.e1; discussion 863-4. doi: 10.1016/ j.jtcvs.2013.12.047. Epub 2014 Jan 15.

2. Contin Educ Anaesth Crit Care Pain (2006) 6 (3): 109113.doi: 10.1093/bjaceaccp/mkl013
3. Nashef SA, Roques F, Sharples LD, et al. EuroSCORE II.Eur J Cardiothorac Surg. 2012;41:734-745.

4. Hillis DL, Smith PK, Anderson JL, Bittl JA, Bridges CR, Byrne JG etal. 2011 ACCF/AHA guideline for coronary artery bypass graft surgery: a report of the American College of Cardiology Foundation/American Heart Association task force on practice guidelines. Circulation 2011;124:e652735.

How to cite this article : Nikhil Mudgalkar. Anaesthesia for off pump coronary artery bypass- Recent updates.Perspectives in Medical Research 2017;5(2):1-2.

Sources of Support: Nil, Conflict of interest: None declared. 